\title{
SWINBURNE'S SEA-PROSE AND THE ANTI-NOVEL
}

\author{
By Irena Yamboliev
}

\begin{abstract}
Sea-Prose
LANGUAGE CAN BE MADE TO REVOLT against its own instrumentality. That is the promise Algernon Charles Swinburne pursues in his unfinished novel Lesbia Brandon, composed in 1859-67 but not published until 1952. Early on in this work, we encounter a passage that perfectly showcases his peculiar and innovative prose style. It is a style that boldly invents its own mechanism of self-perpetuation, and, as it ramifies throughout the novel, turns the text into something other than a conventional narrative - a singular grammar of sensuous perception. The novel's young protagonist, Herbert Seyton, has rounded a corner of a coastal road and comes face to face with the sea. Lesbia Brandon is full of descriptions of the natural environment like this one. It is one of many moments in the novel in which characters encounter, experience, and merge with the seascape. These instances concatenate Swinburne's formal project throughout Lesbia Brandon, a project of translating forces that create patterns in the perceived world into models for prose. The resulting stylistic transformation extends not only to the figurative aspects of Swinburne's language but also to its grammatical and syntactic underpinnings, as peripheral, "accessory" elements become core shaping forces in the prose. This process is at work as Herbert rejoices in the sea-coast and all its enchantments:
\end{abstract}

The long reefs that rang with returning waves and flashed with ebbing ripples; the smooth slopes of coloured rock full of small brilliant lakes that fed and saved from sunburning their anchored fleets of flowers, yellower lilies and redder roses of the sea; the sharp and fine sea-mosses, fruitful of grey blossom, fervent with blue and golden bloom, with soft spear-heads and blades brighter than fire; the lovely heavy motion of the stronger rock-rooted weeds, with all their weight afloat in languid water, splendid and supine; the broad bands of metallic light girdling the greyer flats and swaying levels of sea without a wave; all the enormous graces and immeasurable beauties that go with its sacred strength; the sharp delicate air about it, like breath from the nostrils and lips of its especial and gracious god; the hard sand inlaid with dry and luminous brine; the shuddering shades of sudden colour woven by the light with the water for some remote golden mile or two reaching from dusk to dusk under the sun; shot through with faint and fierce lustres that shiver and shift; and over all a fresher and sweeter heaven than is seen inland by any weather; drew his heart back day after day and satisfied it. (196-97; ch. 2) 
This description consists of just one sentence, containing 209 words and eleven semicolonseparated fragments. With its great length and accumulation of clauses alone, this passage announces that Swinburne's narrative practice will warp the dimensions of prose, stretching its habitual units, the sentence and the paragraph, beyond their usual span. This sentence is remarkable for its almost complete absence of verbs. Almost every one of its verbs ("rang," "flashed," "fed," "saved," "go," "shiver," "shift") appears in a subordinate, defining clause that elaborates on the seascape's features. These verbs, for example, add specificity to the "long reefs" "that rang with returning waves and flashed with ebbing ripples," point to the small lakes "that fed and saved from sunburning," define the immeasurable beauties "that go with [the sea's] sacred strength," and name the lusters "that shiver and shift." At the sentence's conclusion, two predicates finally reveal its raison d'être in terms of plot: the wonders of the sea "drew his heart back day after day and satisfied it." These are the events that motivate the description of the sea, but for most of the sentence's unfolding they are eclipsed, bowled over by the shimmering grammatical elaboration. Swinburne insistently adds adjectives to his nouns, singly and in multiples: "long reefs," "returning waves," "sharp slopes," "small brilliant lakes," "blue and golden bloom," "sharp delicate air," "dry and luminous brine," "faint and fierce lustres." Sometimes the adjectives are comparatives ("yellower lilies and redder roses"), and at others Swinburne piles adjectives all around a noun, surrounding it in a halo of modifiers, as in "the sharp and fine sea-mosses, fruitful," "the hard sand inlaid," and "sudden colour woven." The adjectival imperative is so strong that it infiltrates and dilutes the verbs' efficacy to signal action. In addition to the defining verbs ("that rang," "that fed," "that go," "that shiver and shift"), two more verbs appear near the end of the passage in the form of the participles "girdling" and "reaching." These do not name events but rather describe an enduring arrangement of "broad bands of metallic light" and a recurrent effect of water and light "reaching from dusk to dusk." They, too, contribute to the adjectival mode that dominates this prose.

The abundant adjectives and relative clauses allow what is being described to accumulate detail and nuance as the sentence unfolds. But, importantly, in Swinburne's hands the nuance is more grammatical than it is "realistic." That is, as the parts of the sea - the waves, the "lakes," the water plants, the air - accrue specifications and modifiers, they do not necessarily picture the sea more clearly or accurately. Instead, they emphasize the feel of a movement, the behavior of a collection of material elements that simultaneously move and layer, in concert and in discord, and together make up a perceptual experience of the sea. More importantly, one gets the feel of an aggregate of linguistic elements that enables the physical features of the sea to take shape in the medium of words. Here, the linguistic equivalent of the sea emerges as the subject of this sentence. Strikingly, the elements that make up Swinburne's sea are in fact not reefs, slopes, flowers, and weeds, but specific syntactic combinations, out of which he builds up an arrangement of words to complement the arrangement of these objects in the real world. Just as the flowers and waves of the sea repeatedly configure themselves in time to a rhythm, a linguistic rhythm guides Swinburne's rendering of them by way of repeated combinations of parts of speech. Adjective-noun bundles ("long reefs," "returning waves," "ebbing ripples," "smooth slopes," "anchored fleets," "swaying levels," "hard sand," "shuddering shades") represent a consistent, recurrent structure; a basic, moldable substance. This substance comes rhythmically alive as it gets variously accented by dyads of verbs ("rang... and flashed," "fed and saved") in the first part of the passage; or adjectives both predicative and attributive ("the sharp and fine sea-mosses, fruitful...fervent," "languid 
water, splendid and supine"); or else prepositional and adjectival phrases ("fruitful of grey blossom, fervent with blue and golden bloom," "without a wave," "inlaid with... brine," "woven by the light," "reaching from dusk to dusk"). Swinburne trains his focus on the ebb and flow of these combinations and alternations of words as attentively as on the motion of the waves that originate them.

Even the more "instrumental" elements of this prose - the verbs - also obey Swinburne's formal principle. That is, the few verbs follow their subjects in doubles: the long reefs both "rang" and "flashed"; the small brilliant lakes "fed and saved from sunburning" the sea-plants they house; the lusters "shiver and shift." This is a way to emphasize, by means of grammar, the glimmering, alternating visual components working at the water's edge. These always produce pairs of effects, or, rather, an effect and a counter-effect that restores an earlier state: a wave's passing moves the seaweed in one direction, and the same wave's receding moves the seaweed back again; a flash of light gleams off a ripple in the water, and the same flash of light extinguishes itself as the ripple subsides; the sea-flowers begin to burn in the sun, and the return of the tide saves them from sunburning. At its basis, giving two verbs to each noun is a way of registering the cyclicality of all motion in the sea, the way every movement leads to a counter-movement that reverses it, then recurs. But, in combination with the clustered adjectives, the assonance, and the metrical phrasing that make up this sentence's remarkable architectonics, the paired verbs become part of the formal scheme at work here.

In addition to the syntactical patterning that surrounds nouns with adjectives and relativizes verbs, Swinburne shapes this prose using several sonic patterns. For one, this sea is permeated by alliterative and assonantal chains: "reefs that rang with returning waves," "smooth slopes," "fleets of flowers," "yellower lilies," "redder roses," "blue and golden bloom," "stronger rock-rooted weeds." In addition, these chains form a sequence of generally alternating stresses, roughly iambic or trochaic depending on where one starts counting. For example, Swinburne initially hovers around a mostly iambic rhythm, beginning the phrases of his sentence with unstressed syllables and following them with stressed ones (which I indicate in italics), as in "The long reefs that rang with returning waves and flashed with ebbing ripples." The iambic rhythm gives way from time to time to spondees: "long reefs," "smooth slopes," "coloured rock full," "small brilliant lakes," "sea-mosses," "grey blossom," "spear-heads," "blades brighter." But the alternating stresses recur throughout the sentence and restore a rocking motion, as in "lakes that fed and saved from sunburning their anchored fleets of flowers, yellower lilies and redder roses," "the lovely heavy motion of the stronger rock-rooted weeds, with all their weight afloat in languid water." Toward the sentence's end, when Swinburne turns from enumerating the plants and topographical features and begins to appreciate the sea's exhilarating power and majestic beauty, he increasingly breaks his prose into strings of dactyls and anapests instead of strings of iambs and trochees, as in "levels of sea," "beauties that go with its sacred strength," "like breath from the nostrils and lips of its especial and gracious god," and "shuddering shades" "woven by the light with the water." In combination, these two organizing principles - the syntactical technique of modifying nouns with multiple adjectives or clauses beginning with "that," and the sonic devices of alliteration and metrical modulation - build up a counter-movement that superimposes itself onto the semantic structure of the description. This movement connects terms - noun to noun modified by a shared adjective, or word to word that shares a sound - across the grain of the primary goal of representing the sea. The prose in this passage is occasioned by the realistic object of the sea, by the spatial relations between the coastal features and marine vegetation 
that make up this setting. But, as it hovers and glints about its subject, the prose becomes a force and a subject in itself.

I call this technique, which characterizes Swinburne's most important innovation in Lesbia Brandon, sea-prose, prose that originates in narrating the sea. Sea-prose reveals Swinburne's narrative as a meditation on the structuring capacity of grammatical modifiers. Sea-prose foregrounds formal relations within a cluster of words, and calls attention to the process by which the visual configuration inside the novel's diegetic world gets converted into language. With this prose Swinburne makes us feel, afresh, the strangeness of language, the way it works as a code that demands to be decoded, but at the same time puts up blockages to our decoding in the form of sensual stimuli that carry an interest all their own. The impulse to decode is natural to language, whose forward-moving syntax seeks its own completion in the ending of a period. But Swinburne's prose breaks this forward pace, pushing us to give in to another impulse, the impulse to get to know the sea's own self-sufficient grammar.

\section{Constant Motion in a Static Medium}

SWINBURNE DESIGNED LESBIA BRANDON to be a formal innovation. He describes his novelin-progress in an 1867 letter to his friend Richard Burton as a "scheme of mixed verse and prose - a sort of étude à la Balzac plus the poetry - which I flatter myself will be more offensive and objectionable to Brittania than anything I have yet done" (Letters 1: 224, Swinburne's emphasis). To be sure, the novel's tortuous plot offers plenty to shock. It follows the siblings Margaret and Herbert (Bertie) Seyton, in the wake of their father's death. Both Margaret and Herbert are sensitive and artistic natures, easily moved by music and poetry, and constantly singing ballads and luxuriating in reading poems. The young Bertie lives under the guardianship of Margaret and her husband, Lord Wariston, who have an estate at the seaside. He revels in swimming in the sea, and being buffeted by its violent waves becomes for him analogous to the experience of poetic rhythm. When the Waristons hire a tutor, Mr. Denham, to take Bertie in hand and prepare him for public school, the plentiful floggings Bertie receives at Denham's disciplining hands also become woven into Bertie's phenomenological sense of rhythms experienced bodily. Around these protagonists swirls a company of socialites and arbiters of taste, including the venomous old Lady Midhurst, the sadistic Mr. Linley, and the Brandons, Lord Brandon and his daughter, Lesbia, who gives the novel its title. The novel's plot consists of a series of erotic triangles and displacements of desire, thwarted, onto other objects: Bertie is in love with his sister, but eventually falls in love with Lesbia Brandon, the pagan poetess. Lesbia, who proclaims herself "unmarriageable," is also in love with Margaret Seyton. Denham, likewise, falls in love with Margaret, but discovers that she is his half-sister. The discovery, which makes Margaret inaccessible to him, brings Denham to redouble his punishments of Herbert, who strikingly resembles her. Margaret and Denham eventually have an affair, but when Margaret realizes that they are related Denham commits suicide. Lesbia, meanwhile, wastes away to a slow death by gradual self-poisoning, and at the novel's end both Margaret and Herbert have lost their loves.

Critics have explored the ways Lesbia Brandon's stylistic and especially its lexical peculiarities support its thematic interests. Christopher Lane observes that cycles of excessive passion on the characters' parts become channeled into alternative paths, and in the process perfuse a lexicon of sadomasochism throughout the prose. John Vincent finds that the style of Lesbia Brandon was geared to "make ordinary the dynamics of flogging," using an "emotional 
grammar and vocabulary" that, as Vincent argues, was even more objectionable than the themes (274). The ubiquity of vocabulary associated with corporal punishment signals the novel's preoccupations with flogging as an illegible performance which creates modes of signification that move between the face and the rest of the body. In parallel to these critics' work, I argue that Swinburne's unique grammatical and syntactical transformations, even apart from the semantics, instantiate unprecedented experiments with narrative. I focus on Lesbia Brandon's conspicuous formal project, its radical response to the novel. Swinburne's form is in itself a fundamental and powerful source of shock. He pits a transformational imperative against the novel's representational burden, enumerating colors and textures that behave like so many independent, transposable units, perpetually moving and changing. Where objects in the novel's diegetic plane try to emerge, the prose tends to thwart that emergence. As it diffuses objects' qualities over multiple, continuously modulated linguistic units, the prose coalesces as an entity, a force, an occasion in its own right.

The procedure of extracting elements from their original substrate and giving them an independent life as forms is salient in Swinburne's poetry, and, indeed, Swinburne's stylistic innovations have been discussed most extensively in relation to his verse and critical prose. Jerome McGann has illuminated how Swinburne invented a new prosodic technique in response to Wagner's theory about the rapprochement of poetry and music. Especially in "Anactoria" and Tristram of Lyonesse, but also throughout his verse, Swinburne builds a "scheme of movement and modulation" in which "verbal units - words, word phrases, and even sentential units - are handled primarily as prosodic rather that semantic elements, with grammar therefore emerging as a formal rather than a logical structure" ("Wagner, Baudelaire, and Swinburne" 627). This poetic "scheme of movement and modulation" combines a repertoire of words in various permutations, such that words seem to "give up all semantic fixity" and proliferate "largely as phonemic counters" (630), keyed to "the transformational rule" they instantiate (629). My reading reveals what happens when this compositional technique is imported into prose, where it creates distinct ramifications.

My argument complements Lene Østermark-Johansen's work on the style of Swinburne's critical prose, which explores how in his essays on Florentine art Swinburne stylistically approximates painterly devices like contraposto and the figura serpentinata. ${ }^{1}$ Alliteration, the repetition of words throughout successive sentences, and series of antitheses - that is, words used in the same sentence as their antonyms, or in sentences immediately succeeding each other - add up to what Østermark-Johansen calls a "serpentine" style, a style that evokes mimetically the heavily-coiled, twisting postures of the figures in the drawings by Leonardo and Michelangelo that Swinburne describes. Østermark-Johansen does justice to "Swinburne's highly idiosyncratic synthesis of verbal and visual form" (49). I expand this line of study to reveal the surprising intersection of visual form with literary form in Swinburne's novel. Swinburne converts into language a force that shapes the visual environment, the sea, to produce a different kind of prose - sea-prose - with distinct grammatical and syntactic features. Instantiated in a long duration, as long as a narrative lasts, this style modeled on the sea unleashes language's pattern-making capacities, estranges narration, and ultimately works against plot.

In writing his mixture of verse and prose, Swinburne gives free reign to the pleasure of elaboration that Walter Bagehot, writing about the poetry of Alfred Lord Tennyson and Robert Browning in 1864, called "ornate art." A type of following-through on existing lines leads to "the style of miscellaneous adjunct," which "wishes to surround the type 
with the greatest number of circumstances which it can bear. It works not by choice and selection, but by accumulation and aggregation" (343). Bagehot recognizes that any object or person occurring in language contains possibilities for specification. Ornateness results when the artist takes up as many of those possibilities as he possibly can, syntactically and grammatically. Bagehot's example of ornate art is a segment of Tennyson's Enoch Arden, one 215-word sentence (twenty-eight lines of blank verse) that lists the various sights and sounds the sailor Enoch sees while waiting for a ship -

The myriad shriek of wheeling ocean-fowl,

The league-long roller thundering on the reef,

The moving whisper of huge trees that branch'd

And blossom'd in the zenith, or the sweep

Of some precipitous rivulet to the wave...(641 11. 579-83)

- and no ship comes. Ornate art, as Bagehot describes it, gives a fascination to objects by imaginatively constructing them as visual arrangements that take time to fully take in. It creates "a gay confusion that doesn't exist in the real world" (348) by proliferating details, a greater number of details than normal sentence structure can keep up with. Bagehot was writing about poetry. But his example of ornate style has the features - periodic sentences with many relative clauses; multiple, sometimes compound, adjectives modifying every noun; runs of prepositional phrases - that we would expect in an ornate prose style - and that we find in Swinburne's seascapes. In contrast to Tennyson's, Swinburne's elaboration has a peculiar relationship to visual modes. As George Saintsbury put it, Swinburne "is not by any means consummate or even eminent as a painter in words. His sea-pieces put aside, it may be said of his descriptions that, beautiful as they are, they are rather decorative or conventional than strictly pictorial, they do not bring the actual sight before the eyes with the simple force of Tennyson" (74). Distributing a set of units - sounds and parts of speech - to create contrasts and harmonies, the sentences in Lesbia Brandon do not mimic the shape of the ocean, but the process by which the ocean shapes the environment into a mosaic of fluctuating spots of light, shingle, and color. Swinburne elaborates by extracting some elements of the natural world and "conventionalizing" them to preserve just their general geometric shapes rather than the particular morphology of any one specimen. Voraciously taking up the natural world of the sea and shore, as well as the world of sensation and thought, he abstracts and refines them into simple shapes for his arrangements. In this way Swinburne's style represents a treatment of his medium - language - that seeks out its physical limits. Syntactic and aural effects create a movement of recurrence and of echo. They are given to the sea's qualities of dynamism, cyclicality, and accumulation, and they cause these formal qualities to proliferate throughout the remainder of the novel.

Lesbia Brandon discards teleologically-progressing sequences of events and instead offers - and sustains - a relationship with the physical environment. It converts the rhythms of light shimmering into the rhythms of the novel. Causality and coincidence take on strange proportions in this text: causes are slight, and coincidence so abundant as to drown out meaning. All the main characters - Herbert Seyton, Margaret Seyton, Lesbia Brandon, Denham - turn out to be related to each other, a coincidence that diminishes the importance of plot by implying that how people become joined into family groups is not important: from the start they are positioned in a predetermined configuration. In tracing, instead, his 
characters' responses to their visual environments, Swinburne creates a concept of character as a center of continuous perception. The unfolding process of perception itself becomes the flow and flux of the sea-prose. This phenomenon in Lesbia Brandon is "poetic," if we see it as a version of what Yopie Prins describes as the central mechanism of Swinburne's poetry. Prins argues that Swinburne's analogy between Sapphic love and the process of making poetry produces diffusion, at least as a theme and at times also as a formal effect (113). In Lesbia Brandon, too, the various interpersonal relationships make for a "scattering movement too diffuse to be contained within any single body" (113). In contrast to the poetry, in this novel the scattering does not become "formalized into a metrical pattern," but instead creates a sustained "structure of repetition" that puts meaning through "reiteration[s] of its own undoing" (113).

Porting Swinburne's prosodic technique into the novel, Lesbia Brandon makes the sea into a linguistic subject that stands against other narrative, plot-oriented moments. Seaprose uses the slight armature of story to give rise to expanses of patterned description that far outstrip the plot-advancing narration, and produce two important alterations to the forces we think of as structuring the narrative. When Swinburne describes the sea, sea-prose becomes a pivot for the relation of the characters to the environment. Landscape ceases to be background and becomes an equal participant in the events unfolding. But that is not all. Sea-prose infiltrates narrative even when Swinburne is not describing the sea, and in these moments it transforms the relations of characters to other characters. Sea-prose agitates against the notion of characters as individuated persons, and, by extension, against the novelistic convention that would give those persons' interactions narrative priority over other, impersonal relations. About this I will have more to say in a moment. First, a look at the mechanism by which sea-prose carries through the novel. Adjectives are the stylistic units that make sea-prose continue to be active in Swinburne's descriptions of subjects other than the sea.

\section{The Adjectival Topic: Some Quantitative Findings about Lesbia Brandon}

THE TWO CENTRAL ASPECTS of Swinburne's innovative prose style, its abundance of adjectives and its deployment of color, occupy similar positions within the hierarchies of their respective media, language and visual art. Nouns and verbs can be thought of as equivalent in importance to line and shape. Nouns are the commonest words in text, and verbs are fundamental "in the sense that they function as head in clause structure" (Huddleston and Pullum 526). Every noun can also be transformed into a verb, which further solidifies verbs' superiority in the hierarchy of parts of speech. But, Huddleston and Pullum continue, "there are not enough nouns and verbs to express every shade of meaning needed." Thus, "the necessary finer gradations of meanings" are expressed by means of adjectives and adverbs (526). Like color in visual art, adjectives and adverbs are entities without which it is still possible to write perfectly grammatical sentences and communicate effectively. But, there are several things that adjectives are especially able to do. First, "adjectives almost always denote states" (526), and they can capture nuances like the permanence or impermanence of those states. They can reflect the results of time's passing on the objects and persons it affects. That is, differently from verbs, which directly indicate sequence, adjectives and adverbs can indicate more finely the effects of narrative sequentiality on the objects and people who move through any sequence. 
Adjectives can be distributed in several ways in relation to the nouns they modify, and thus offer multiple ways of adding specificity to a noun. Attributive adjectives come before their nouns and register essential properties, as in Swinburne's "sharp and fine sea-mosses." Predicative adjectives, on the other hand, come after verbs, often copular verbs (is or seems), and can thus mark qualities that nouns have in specific moments, transitory qualities, for example, "his grasp was close and retentive." One other feature makes adjectives special. Like colors, which can be varied into shades and tints, adjectives are often gradable. Not only do they take inflection into comparatives and superlatives, but also, like adjacent colors that mutually modify each other, some adjectives which have originally been absolute, like perfect, complete, or unique, become gradated in usages like "a more perfect union" or "the most unique invention."

Adjectives delay the forward movement of narrative, dilating its vector to open up space for specification and qualification. Combining with a noun, they create a new, emergent object, qualitatively different from and more precise than its component parts. In Lesbia Brandon, Swinburne wields adjectives toward such exquisiteness of precision - and with such a magnitude - that they become, in themselves, a structuring force - one that can be detected using quantitative methods. Analyzing Lesbia Brandon with the computational tool known as Topic Modeling reveals that the adjective is a fundamental organizing element of the novel, as prominently efficient as any theme, character, or subject. The topic modeling approach works by using statistical data about the frequency and collocation of all the words that comprise a corpus of texts to identify words that consistently collocate within that corpus. ${ }^{2}$ Words that collocate frequently get aggregated by the tool into distinct "topics," which usually correspond to what we normally call themes, shared by the texts in the corpus. In terms of output, each topic gets presented as a series of words arranged in decreasing order of importance to the topic. That is, the words that appear earlier in the series contribute more to structuring the topic of which they are a part than do the words that appear later.

This approach can show macro-scale associations that may not be perceptible when only local occurrences of words are examined. It is a technique typically applied to large and diverse textual corpora in which patterns cannot be easily registered at a regular reading. And yet, topic modeling yields interesting results when applied to Lesbia Brandon alone. ${ }^{3}$ It reveals several unsurprising topics, and one very striking pattern. First, as expected, topic modeling lets us see themes we easily recognize as central, for example, the connection between poetry and flogging. Margaret and Bertie, when they sing songs together, have the same reaction: "The verses had bitten and stung them sharply; they felt through all the nerves of body and soul the delight of mad and violent devotion, and their blood beat with the senseless and splendid rapture of martyrs conscious of a losing cause" (Lesbia Brandon 257; ch. 3). And the young poetess Lesbia later muses, "Things in verse hurt one, don't they? hit and sting like a cut.... It's odd that words should change so just by being put into rhyme. They get teeth and bite; they take fire and burn" (333; ch. 15). Topic modeling identifies the theme of verse's connection to pain and presents it as the following series of terms:

Words, back, tears, close, hurt, bitter, great, pure, room, stung, verses, late, beat, burn, torment, virtue, caught, write, double, model, perpetual.

What is remarkable about Lesbia Brandon is that in addition to topics corresponding to characters, scenes, or themes, the topic modeling approach identifies a "topic" comprised 
mainly of adjectives. This is a striking result of such analyses, because a single part of speech is rarely sufficient to constitute a topic. Moreover, among parts of speech adjectives typically have a secondary role, as mere modifiers of the nouns and verbs that actually mold the topic. This unique adjectival topic consists of the following words:

Full, soft, colour, tender, long, green, dark, delicate, fine, clear, blue, gold, pale, shade, eyebrows, part, allay.

This set features only five words that are not adjectives (colour, shade, eyebrows, part, allay). Most of them appear quite late in the series, which means they are quite unimportant in shaping the topic as a whole. Each of these adjectives occurs throughout Lesbia Brandon, cropping up in very different parts of the plot - in the portrait of Margaret at its opening, in the sea-prose, in Lesbia's death scene - and indiscriminately attaching to multiple objects. Approached via the computational method of topic modeling, the adjective comes into focus as a fundamental shaping force in Swinburne's prose. As an adjectivally-driven mechanism, sea-prose can continue unbounded, stringing together bundles and chains of adjectival and adverbial phrases without limit. Thus adjectives are central to sea-prose's accomplishment of conceptual, syntactic and aural patterns that depart from their realistic occasion and overwhelm it, unashamedly expanding paragraphs over multiple pages, making sentences billow within the paragraph, and allowing the adjective-adjective-noun triplet to take over representational coherence. Adjectives make the prose fluid, capturing the sea's continuously dynamic production. Sea-prose takes inspiration from a quality of movement, and replicates that quality in a syntactic process that then can bring movement into any other object the prose sets out to render.

\section{Blazon: Description's Sea-Change}

THE SEA-LIKE LINGUISTIC DYNAMISM takes center stage in Swinburne's unique variation on blazon, in which sea-prose's influence dramatically transforms visual arrangements that usually sustain a great deal of interpretation: faces. The blazon is rooted in rhetorical traditions of describing heraldic arms, and poetic traditions of describing an object by cataloguing its parts and their various beauties. The portrait blazon was popularized by the French sixteenthcentury blasons anatomiques du corps feminin, collections of lyric poems, each praising a single, separate part of the beloved's body: the blazonneur would render his love object's lips, eyes, cheeks, breasts; and, in the Petrarchan tradition, the exuberant, luxuriant figuration would substitute for physical possession. ${ }^{4}$ But, whereas the Elizabethan blazon is "geared towards setting forth, part by part, a total beauty" (Bennett 303) that, though fragmented, remains comprehensible as a human form, in Swinburne's hands what takes priority is the exquisite differentiation of colors, planes, and curves. And while typically the blazon trains the narrative gaze onto a face or body which it treats as unchanging, then directs prose's eye sequentially over that face's various parts, Swinburne disarranges this distribution of motion and stasis by dissolving blazon in sea-prose. Encountering the face, the sea-prose sets it aswim and produces an object whose qualities shimmer in the very prose that renders them. Each color specified induces influxes of additional colors, further nuances, and proliferating tones, and the character's portrait resolves into a flux of shifting, moving shapes. The blazon is an impersonal portrait by means of which Swinburne frees faces from their individual 
interiors and releases them to interact as palpable, tantalizing concentrations of color. The novel opens with this description of Margaret Seyton's face:

\begin{abstract}
Her eyes had an outer ring of seeming black, but in effect of deep blue and dark grey mixed; this soft and broad circle of colour sharply divided the subtle and tender white, pale as pure milk, from an iris which should have been hazel or grey, blue or green, but was instead a more delicate and significant shade of the colour more common with beast or bird; pure gold, without alloy or allay, like the yellowest part of a clear flame; such eyes as the greatest analyst of spirit and flesh that ever lived and spoke has noticed as proper to certain rare women, and has given for a perpetual and terrible memory to his Georgian girl. In a dark face, southern or eastern, the colour should be yet rarer, and may perhaps be more singularly beautiful than even here, where it gave to the fair and floral beauty of northern features a fire and rapture of life. These eyes were not hard or shadowless; their colour was full of small soft intricacies of shade and varieties of tone; they could darken with delicate alteration and lighten with splendid change. The iris had fine fibers of light and tender notes of colour that gave the effect of shadow; as if the painter's touch when about to darken the clear fierce beauty of their vital and sensitive gold, had paused in time and left them perfect. The pupil was not over large, and seemed as the light touched it of molten purple or of black velvet. They had infinite significance, infinite fervor and purity. The eyelashes and eyebrows were of a golden brown, long and full; their really soft shade of colour seemed dark on a skin of white rose-leaves, between a double golden flame of eyes and hair. Her nose was straight and fine, somewhat long, and the division of the nostrils below a thought too curved and deep, but their shell exquisite in cutting and colour...(189-90; ch. 1)
\end{abstract}

This passage, like the excerpt of sea-prose I considered previously, begins by stretching the usual proportions of sentences: its first sentence is 118 words long. It extrapolates the convention of blazon by delineating minutiae, not just parts of the body and face, but threads of color within the iris and shades of black within the pupil. The description shuttles among a few key ingredients ("colour," "dark," "light," "gold," "carved," "curved," "seemed") which it presents in a thoughtful, intentional arrangement. The pupil, changeable in changeful light conditions, "seemed as the light touched it of molten purple or of black velvet." The "shell" of the nostrils is "exquisite in cutting and colour," as if crafted by a sculptor or rendered by a painter. The eyelashes and eyebrows are set, almost within a frame, "between a double golden flame of eyes and hair."

The passage lays bare the process of grammatical and syntactic compounding that underlies its aesthetic "suggestions." Clauses succeed each other across semicolons with no hypotaxis, refusing to resolve into a hierarchy. The prose delights in making sequences of objects that are, in themselves, highly wrought. It arranges adjectives around nouns in a variety of ways, simply, when it modifies a noun with a single adjective, or more complexly with a pair of adjectives joined by a conjunction, as in "soft and broad circle of colour," "subtle and tender white," "full and frank," and "pale but capable." More complex modifications still add simile ("the subtle and tender white, pale as pure milk") and even counterfactuals ("In a dark face, southern or eastern, the colour should be yet rarer"). Comparatives accumulate, culminating in excesses like "perhaps more singularly beautiful," where two adverbs, one of them already comparative, modify a fervent adjective. Syntax proliferates conceptual alternatives: a dark face as opposed to a light face; a southern or eastern face in contrast to a northern face; pallor versus capability; delicacy as opposed to predictability. These evoked alternatives produce chains of aesthetic speculation and fantasy in the midst of the description - "an iris which should have been hazel or grey, blue or green, but was instead a 
more delicate and significant shade of the colour ..." - and the new alternatives cascade into additional specifications and similes - " ... the colour more common with beast or bird; pure gold, without alloy or allay, like the yellowest part of a clear flame." As it suggests an almost infinite variability of types and degrees, this prose becomes an exercise in modification and self-perpetuation. The luxuriant description goes on for another page, and it seems it could continue its minute delineations endlessly.

This blazon shows the gesture of embellishment that drives Lesbia Brandon, beginning with a functional "stem" (one must describe the heroine) and wreathing it with flowers. The prose elaborates even before it has any story to hang on. The opening portrait pulls language forth from a starting point that is in itself arbitrary: Margaret Seyton isn't in fact the heroine of this text; the novel bears another's name. And yet, actually this "other" comes no closer than Margaret to filling the shoes of a protagonist. Lesbia Brandon is not the character with whom we spend the greatest amount of time, ${ }^{5}$ or, more to the point, the character whose point of view filters the diegetic world for us. Her desires and motivations are not the ones in relation to which we evaluate the causes and consequences of events. It is Bertie Seyton's palpitating view of the world and the people around him that gives meaning to what happens. And yet, it's not Bertie with whom Swinburne opens his novel, either! Margaret at best ranks third in a traditional order of rights to the text's first, and lengthiest, description. In starting his novel with an object that seems not to deserve this place of honor, Swinburne signals that disrupting narrative convention will be the bread and butter of his writing practice. He opens with someone who is, first and foremost, a superior substrate for his prose to embellish, and the language proceeds according to a mechanism that it generates internally. As though the subject matter were irrelevant, Swinburne offers a lesson on the kinds of forms blazon is capable of taking: the adjectives a face is capable of attracting, the objects to which it is assimilable, and the kind of syntactic units it is capable of eliciting. The thrum of this formal engine reverberates through the rest of the novel. Each character Swinburne describes hereafter seems like an explicit extension of the excess of this, first, blazon, which does not mark a uniquely excessive specimen but becomes a new norm. Swinburne confounds the system that would resolve foci of description like Margaret into categories like protagonist, antagonist, climax, filler - in other words, disrupts any index of narrative hierarchy or directionality. Or else, we see the narrative hierarchy back there, but only through a distorting glass of ornamental prose.

But more than just distorting a conventional descriptive technique, this transformation of blazon reshapes the novel's sense of what characters are. Sea-prose fundamentally redraws the lines along which the relations of characters to other characters unfold. Like the features of a seascape, characters might combine to form larger wholes, but their belonging in these combinations doesn't depend on their being unique individuals. Their configuration into family groups or erotic groups is not a culmination of their personal or ethical histories. Instead, the characters' genetic relatedness offers a mechanism of connecting them that, from the perspective of the narrative, is as contingent, visual, perceptually affective, and ethically unbound as the links among the sea's parts. In applying sea-prose to objects other than the sea, then, Swinburne radically recasts the relations most important to the novel. Rather than interpersonal relations, Swinburne gives us chromatic, textural, and rhythmic relationships. ${ }^{6}$

Swinburne's importing of sea-prose into regions of the novel that do not depict the sea resembles an effect Sharon Cameron traces as it works through Herman Melville's Billy 
Budd: a "suffusion of a property across the natural, the human, the divine" (190) that renders character "inconsequential - not transcended but exceeded by diffusive aspects of the prose that permeates distinction" (194-95). Melville "treats persons as if they were not governed by a set of constraints that differentiate them from other phenomena, as if ... a person were not different from a stone or a manifestation of light" (182). His method is based in "Features which apply to characters (who represent individuals and types) [and] also apply to elements that lie outside of the characterological" (182). This is an apt description of Swinburne's technique, too, except that while for Melville the "properties" suffused across characters and non-characters are metaphysical - "evil," "innocence" - the properties that interest Swinburne are physical, visual. Both authors level the human and the non-human, but on different planes. Melville's impersonality points toward a "global force" which presumes that personal character is made of the same essence as all other phenomena, which share with human persons a Schopenhauerian will. Swinburne, on the other hand, anchors impersonality in a ubiquitous capacity for sensual impression - for giving and receiving pleasure and pain, at the hands of the natural environment and of each other - which all his characters share, and which Swinburne works to share with us, via language. Individual personality recedes into the background so that what moves into the foreground is the medium that allows us to experience characters or landscapes in the first place. For Swinburne, renderings of the world in prose, no less than in rhyming verses, "have teeth," and one of Swinburne's linguistic achievements in Lesbia Brandon is, if you will, to make narrative turn around and bite us.

\section{Land-Prose and Narrative Brutality}

SEA-PROSE PITS AN ENDLESSLY continuing narration-as-sensation against emplotment and, in so doing, produces a version of character-as-sensation too. Left to expand by its own internal laws, sea-prose could perpetuate itself without stopping: an endless melody. To become a novel, though, this form needs to be shaped according to a different set of priorities. As Lesbia Brandon continues, sea-prose comes under threat by the exigencies of plot. The chapter titled "A Day's Work" is the longest and most finished in Lesbia Brandon, and it introduces Mr. Denham, the tutor the Waristons employ to take Bertie in hand. Denham is supposed to be an agent of the public world to which Bertie will have to get socialized; his task is to ready Bertie for Eton, not least of all the culture of corporal punishment that will accompany his studies there. Denham intrudes into the midst of one of Bertie's most euphoric swims in the sea. Bewilderingly, Swinburne does not separate Denham's entrance on the scene from the medium of the sea, not even with a paragraph break. From the perspective of the narrative, however, this mode of introduction is fitting, since Denham's job will be to curb Bertie's impetuosity, and his swimming:

In thunder that drowned his voice, wind that blew over his balance, and snowstorms of the flying or falling foam that blinded his eyes and salted his face, the boy took his pleasure to the full; this travail and triumph of the married wind and sea filled him with a furious luxury of the senses that kindled all his nerves and exalted all his life. From these haunts he came back wet and rough, blown out of shape and beaten into colour, his ears full of music and his eyes of dreams: all the sounds of the sea rang through him, all its airs and lights breathed and shone upon him: he felt land-sick when out of the sea's sight, and twice alive when hard by it.... It was in this guise that he first met the man who was to rule and form his life for years to come. Drenched and hot and laughing, salt and blown and 
tumbled, he was confronted with a tall dark man, pale and strong, with grey hard features and hair already thinned. (202; ch. 2$)$

We recognize in the beginning of this passage the elements I have been describing, including alliterative chains ("travail and triumph," "furious luxury"), adjectives ("wet and rough," "drenched and hot and laughing, salt and blown and tumbled"), perceptual alternatives ("falling or flying foam," "blown out of shape and beaten into colour"), and cascades of modifying clauses ("thunder that drowned his voice," "wind that blew over his balance," "furious luxury of the sense that kindled all nerves and exalted all his life"). That there is no separation between Bertie's exhilarated tumbling and Denham's arrival shows how irresistible, irrefutable the arrival is. When Bertie notices Denham it is already too late, and though the moderate "met" sets up the moment in which he initially encounters "the man who was to rule and form his life," and tries to soften the intrusion, Bertie in fact "was confronted with a tall dark man." A confrontation sudden and inescapable.

Next comes a portrait of Denham, notable because, unlike the earlier portrait of Margaret, it does not linger over Denham's eyes and face, but moves quickly to more "relevant" features: his strength, athleticism, and coldness. The makings, after all, of an effective tutor, disciplinarian, and socializer: "Mr. Denham had noticeable eyes, clear brown in colour, cold and rapid in their glance; his chest and arms were splendid, and the whole build of him pliant and massive, the limbs fleshless and muscular. But for the cold forehead and profound eyes he seemed rather a training athlete than trained student" (202; ch. 2). Yet despite the prominence of Denham's strong build, the prose returns to his face and describes it counterfactually, trying to find, as it had in Margaret's face, some beauty or enchantment:

The forehead was large in all ways, and the strong prominent bones made the outlines coarse. Nothing in his face seemed mobile but the nostrils; and these were its weakest feature. The nose and mouth had a certain Irish air, corrected by the strong compression of the lips which if relaxed would have changed the whole face; but they never did relax, whether in talking or laughing, drinking or sleeping; they should have been full and soft, and were thin it seemed not because they had grown thin through natural change but by dint of purpose and compulsion. (202; ch. 2)

The lips in particular are points of hope which "if relaxed would have changed the whole face," and which "should have been full and soft." The wishful commentary on their potential aesthetic virtues occasions a sentence much longer than the otherwise austere procession of short sentences. At last, the search for beauty fails and instead uncovers some unsavory signs of morbidity in the skin of this face. The prose interprets them as consequences of Denham's early life: "Life repressed and suppressed strength were not indiscernible after sharp scrutiny of his face. The skin looked blasted and whitened, as if it had once been brilliant and smooth: it was now colourless and dry, lined and flaked with dull tinges of diseased colour" (203; ch. 2). (Even here, the prose cannot help but relish the possibilities for phonemic transformation, and produces the symmetrically modified and semantically disorienting "life repressed and suppressed strength.")

But Denham himself does a great deal of work in Lesbia Brandon's scheme. In its final turn, the portrait of Denham returns to Bertie and describes the effect Bertie suffers when Denham's eyes fall on him. It is as though the eyes deal a physical blow, the first of many Bertie will experience at Denham's hands. Indeed, immediately after registering the effect 
of Denham's eyes on Bertie's skin, Swinburne shifts the prose to focus on the hands, first Bertie's and then Denham's, which are the first site of concrete contact, complementing the contact already made between their eyes:

\begin{abstract}
As his eyes fell on Herbert, the boy felt a sudden tingling in his flesh; his skin was aware of danger, and his nerves winced. He blushed again at his blushes, and gave his small wet hand shyly into the wide hard grasp of the strong and supple fingers that closed on it. Denham had broad hands on which the veins and muscles stood in hard relief; well-shaped and strong, good at handling oar and bat, the nails wide and flat and pale, the joints large and the knuckles wrinkled; hands as significant as the face. The soft sunburnt hand with feminine fingers lay in his almost like a roseleaf taken up and crushed; his grasp was close and retentive by instinct; he kept hold of the boy and read his face sharply over, watching it redden and flinch. (202-03; ch. 2)
\end{abstract}

The prose here exposes its reason for focusing on Denham's hands: they are "hands as significant as the face." And as Bertie offers his small hand into Denham's, the passage continues to "read" Denham's hands for their sturdy construction, their prowess at handling difficult instruments, and the quality of their instinctive grasp - just as Denham reads Bertie's face "sharply over." This portrait values face and hands equally and describes them simultaneously, recalling Margaret's blazon, but also departing from that mode. Where the earlier portrait saw the face as having been worked by the hands of a masterful painter into luminous, beautiful configurations, the prose that renders Denham emphasizes what work we can expect will be done by Denham's well-crafted hands. Their capability contrasts with the willed stiffness and immobility of his face. Denham, then, is an agent and a worker rather than a perceiver.

Denham does a great deal of work in Lesbia Brandon's scheme. Within the novel's world, he does not altogether succeed in enforcing the rules of well-mannered society, because he falls in love with Bertie's sister, Margaret, who is also Denham's half-sister. The attraction consumes him in intense sensations and emotions, and so the sea-prose at times attaches to him as it does to Margaret and Bertie. Denham does, however, succeed in enforcing the reign of the genre that forms the container for all of these floating, mutually modulating impressions. He initiates a plot of erotic desire and subsequent adultery, incest, and suicide. Crucially, Denham's desire becomes plot in a way that Bertie's desire for the sea, or Margaret's passion for ballads, does not, because the tutor's yearning is directed toward human beings. This redirection of desire is enough to derail the text from tracing the private mind's inner movements and impressions, and train it toward reporting how the relations and affairs between characters play out on the stage of their social circle. Violence accompanies the change at multiple levels. On the diegetic plane, Denham's role as tutor to Bertie adds the publically sanctioned violence of flogging to the more "incidental" and aesthetic violence of the beatings Bertie gets from the sea. Also, Denham's love for Margaret is as physical and bodily as Margaret's and Bertie's loves of sea and song. But, unlike their loves, Denham's love can produce a bodily effect in its object. It can exact a physical response from that object. The effects of a flogging or of an affair are visible, and thus generate plot. With Denham's force impacting it, the elaborative prose merges into the novel of manners, and henceforward contends with the narrative sequences of Bildung for Bertie and adultery for Margaret, which Denham has set into motion. Denham shines a light on brutality as a practice constitutive of narrative, and particularly of emplotment. 
THE BURDEN OF SWINBURNE's METHODOLOGY in Lesbia Brandon, and of mine in this essay, is to see objects in their intimate, minute details. The phenomenology of looking into the sea, or into an eye, and perceiving it as made up of light is a central concern of this novel. In his multi-centered, adjectival prose, Swinburne privileges the continuous exfoliation - in the etymological sense of developing into foliage - of sensations, and of the sights, sounds, and textures of the diegetic world that produce them. One effect of such an impersonal conductance of the perceived environment is an insistence that natural surroundings deserve the closest attention.

Nevertheless, more than a descriptive analogy for Swinburne's rendering of landscape, sea-prose emerges as a formulation of formal choices with important stakes. Where we expect narration to individualize characters and display their subjective interiors, sea-prose makes them perceivable in terms of contingent relations that spring from their transient, physical, visual qualities. As it transforms blazon, sea-prose creates a sort of ecotone between character and environment and also between character and character. The forces that shape the plots of both humans and landscapes taper toward a single fundamental set of impersonal, rhythmic sculpting mechanisms. Sea-prose enables Swinburne to create within the novel what Jerome McGann describes as a poetry divested of "all personal qualities" (Swinburne: An Experiment 59), which can bring about "the revelation not of concepts but of perceptions" (78).

A luxuriant, radically disorienting experience of prose, the novel, in Swinburne's hands, drives at the heart of questions about how far it is possible to go in imitation of the external world. As we read Lesbia Brandon, we become aware of a dark inverse relationship whereby being incredibly true to form means destroying verisimilitude, representational coherence, and plot. Confronting the novel, sea-prose shows us what's normally left out: unencumbered, ever-expanding perception, desire, and impersonal, sensual relationality. By understanding sea-prose as activated in parts of the novel that seemingly have nothing to do with the coast, we gain insight into how Swinburne made his works of fiction, and not only his critical prose, vehicles of what Andrew Kay aptly calls impressionistic formalism: a commitment to seeing "literary forms not as self-contained entities, but as engaged in a process of challenging and ideally overturning - the moral and political" - and, I would say, phenomenological "ideologies of the cultures out of which they spring" (292). Sea-prose emerges as Swinburne imagines sensory impression working in a feedback loop not only with emotion, but also, fruitfully, with form. Out of the form-ness of this particular kind of prose, a new narrational process arises and revises the novel's contours.

\section{Stanford University}

\section{NOTES}

1. For further discussion of the revolution Swinburne brought to English critical prose, see also McGann's Swinburne: An Experiment and Maxwell's Swinburne.

2. Matthew Jockers describes topic modeling as the identification of "words that tend to co-occur together in multiple places in multiple documents" (124). The topic modeling algorithm, formally known as 
latent Dirichlet allocation (LDA), "derives word clusters using a generative statistical process that begins by assuming that each document in a collection of documents is constructed from a matrix of some set of possible topics. The model then assigns high probabilities to words and sets of words that tend to co-occur in multiple contexts across the corpus" (Jockers 123).

3. I performed a topic modeling analysis by treating the whole novel as the "corpus" and each chapter (or chapter fragment) as an individual document within that corpus. Two experiments sorted the novel into 20 topics and 30 topics respectively, each time confirming the finding I describe here. My deep thanks to Ryan Heuser for his generous help in running these analyses.

4. Vickers offers a concise history of the blazon in "'The blazon of sweet beauty's best" (95).

5. Granted, Swinburne may have included more extended scenes for Lesbia in the manuscript pages that his friend Theodore Watts-Dunton refused to return to the writer, apparently fearing they were too scandalous to publish. Those pages remain lost to us. See Wilson's introduction to The Novels of A.C. Swinburne (23-24), and Burnett's "Some Reflections."

6. Helsinger finds Swinburne pushing toward impersonality in another of his formal decisions in Lesbia Brandon, that to embed ballads and songs into multiple scenes, making his "scheme of verse and prose mixed" spatially and typographically overt. As Helsinger shows, embedded songs, which remind us of song's ancient oral tradition in contrast to the single-authored writing which surrounds them, "are indeed not the exclusive expression of any single voice, but rather impersonal or perhaps more accurately, multipersonal, multiply voiced" (158). By having his characters sing, replacing individualizing utterance with a focus on the bodilyness of singing, Swinburne complements what I have described as a technique of evacuating the individual self's interiority by using equally patterned, chromatic prose to narrate both landscape's behavior and characters' interactions with each other.

\section{WORKS CITED}

Bagehot, Walter. "Wordsworth, Tennyson, and Browning; or, Pure, Ornate, and Grotesque Art in English Poetry." The Collected Works of Walter Bagehot. Vol 2. Ed. Norman St. John-Stevas. Cambridge: Harvard UP, 1965. 318-66.

Bennett, Chad. "Oscar Wilde's Salome: Décor, Des Corps, Desire.” ELH 77.2 (Summer 2010): 297-323.

Burnett, T. A. J. "Some Reflections on the Text of Swinburne's Unfinished Novel, the So-Called 'Lesbia Brandon." Victorian Poetry 47.4 (2009): 777-86.

Cameron, Sharon. Impersonality: Seven Essays. Chicago: U of Chicago P, 2007.

Helsinger, Elizabeth. "Song's Fictions." The Yearbook of English Studies 40.1/2 (2010): 141-59.

Huddleston, Rodney D., and Geoffrey K. Pullum. The Cambridge Grammar of the English Language. Cambridge: Cambridge UP, 2002.

Jockers, Matthew Lee. Macroanalysis: Digital Methods and Literary History. Urbana: U of Illinois P, 2013.

Kay, Andrew. "Swinburne, Impressionistic Formalism, and the Afterlife of Victorian Poetic Theory." Victorian Poetry 51.3 (Fall 2013): 271-95.

Lane, Christopher. "Love's Vicissitudes in Swinburne's Lesbia Brandon." The Burdens of Intimacy:

Psychoanalysis and Victorian Masculinity. Chicago: U of Chicago P, 1999. 73-92.

Maxwell, Catherine, and Isobel Armstrong. Swinburne. Tavistock: Northcote House, 2006.

McGann, Jerome J. Swinburne: An Experiment in Criticism. Chicago, U of Chicago P, 1972.

. "Wagner, Baudelaire, Swinburne: Poetry in the Condition of Music." Victorian Poetry 47.4 (2009): 619-32.

Østermark-Johansen, Lene. "Swinburne's Serpentine Delights: The Aesthetic Critic and the Old Master Drawings in Florence." Nineteenth-Century Contexts 24.1 (2002): 49-72.

Prins, Yopie. "Swinburne's Sapphic Sublime." Victorian Sappho. Princeton: Princeton UP, 1999. 112-73.

Saintsbury, George. "Mr. Swinburne.” Corrected Impressions: Essays on Victorian Writers. 1895. Freeport:

Books for Libraries, 1972. 60-78. 
Swinburne, Algernon C. Essays and Studies. Third ed. London: Chatto and Windus, 1888.

. Lesbia Brandon. The Novels of A.C. Swinburne. Ed. Edmund Wilson. New York: Farrar, Straus and Cudahy, 1962. 185-377.

Swinburne, Algernon Charles, and Cecil Y. Lang. Letters. New Haven: Yale UP, 1959.

Tennyson, Alfred T., and Christopher Ricks. The Poems of Tennyson. Vol. 2. Harlow, Essex: Longman, 1987. Vickers, Nancy. “'The blazon of sweet beauty's best': Shakespeare's Lucrece." Shakespeare and the Question of Theory. Ed. Patricia Parker and Geoffrey Hartman. New York: Methuen, 1985.

Vincent, John. "Flogging is Fundamental: Applications of Birch in Swinburne's Lesbia Brandon." Novel Gazing: Queer Readings in Fiction. Ed. Eve Kosofsky Sedgwick. Durham: Duke UP, 1997. 269-95.

Wilson, Edmund. Introduction. The Novels of A.C. Swinburne. By Algernon C. Swinburne. New York: Farrar, Straus and Cudahy, 1962. 3-37. 